SI'SOMOS AMERICANOS

Revista de Estudios

Transfronterizos
Volumen XIX, número 1,

enero-junio 2019.

Recibido: 17 de abril 2018.

Aprobado: 09 de abril 2019

\title{
América Latina frente a un cambio de época*
}

\section{Latin America before a change of time}

\author{
Raúl Bernal-Meza** \\ Instituto de Estudios Internacionales, Universidad Arturo Prat, Chile.
}

Cómo citar este artículo: Bernal-Meza, R. (2019). América Latina frente a un cambio de época.

Si Somos Americanos, 19(1), pp.85-109.

DOI: $10.4067 / \mathrm{S} 0719-09482019000100085$

\section{Resumen}

La reconciliación diplomática entre Estados Unidos y Cuba y la visita de Obama a La Habana constituyen un quiebre -político, ideológico, eidético y de paradigmas- que, siguiendo la argumentación de Hobsbawm sobre los períodos históricos del siglo XX, marcan un "cambio de época" en las relaciones internacionales hemisféricas, dando inicio a una reconfiguración cuyas tendencias están determinadas por los recientes recambios de gobierno en distintos países de América Latina y, fundamentalmente, por el proceso de transición hacia un nuevo orden de relaciones internacionales y hemisféricas que ha impulsado Donald Trump. En este contexto, lo nuevo, que representa el "cambio de época", está determinado por el ejercicio del poder por parte de Estados Unidos, entre una praxis de poder social, de mayor multilateralismo, cuya mejor expresión fue la reconciliación diplomática entre Estados Unidos y Cuba, pero también por el retorno al unilateralismo, el proteccionismo y la interpretación de un poder norteamericano sin igual, por parte de Washington, bajo la administración del presidente Trump. El texto contribuye a la

\footnotetext{
Este trabajo corresponde a la versión final de la exposición realizada en el congreso de LASA (Barcelona, mayo de 2018), con apoyo y financiamiento de la Universidad Arturo Prat.

** Licenciado en Ciencias Políticas y Sociales, Universidad de la Sorbonne-Nouvelle. Máster en Economía, Universidad de la Sorbonne-Nouvelle, París III y en Relaciones Internacionales, FLACSO, Argentina. Doctor en Sociología, Pontificia Universidad Católica, Argentina. Profesor Titular de la Universidad Arturo Prat y de la Universidad Nacional del Centro de la Provincia de Buenos Aires. Profesor de la Universidad de Buenos Aires. Correo electrónico: bernalmeza@hotmail.com
} 
identificación del proceso de cambios -globales, hemisféricos y regionales- posteriores al "cambio de época" y al análisis sobre respuestas que están surgiendo en Sudamérica frente a los nuevos escenarios globales y regionales.

Palabras clave: relaciones internacionales, América Latina, políticas exteriores.

\begin{abstract}
The diplomatic reconciliation between the United States and Cuba and Obama's visit to Havana constitute a break -political, ideological, eidetic and paradigmatic- that following the argument of Hobsbawm (2007) on the historical periods of the 20th century, mark a "change" of epoch "in international hemispheric relations; starting a reconfiguration whose tendencies are determined by the recent re-changes of government in different countries of Latin America and, fundamentally, by the process of transition towards a new order of international and hemispheric relations that Donald Trump has promoted. In this context, the new, which represents the "change of time," is determined by the exercise of power by the United States, between a praxis of social power, of greater multilateralism, whose best expression was the diplomatic reconciliation between the United States and Cuba; but also by the return to unilateralism, protectionism and the interpretation of a US power without equal, by Washington, under the administration of President Trump. The text contributes to the identification of the process of changes - global, hemispheric and regional - subsequent to the "change of time" - and to the analysis of responses that are emerging in South America in the face of new global and regional scenarios.
\end{abstract}

Keywords: international relations, Latin America, foreign policies.

\title{
Desarrollo
}

A comienzos del nuevo siglo, en un balance sobre el "estado de situación" de América Latina, desde perspectivas intra y extrarregionales, luego de una década -la de los años noventa- de fuerte homogeneidad en el modelo de desarrollo económico, políticas exteriores convergentes con el internacionalismo liberal norteamericano, buenas relaciones con Estados Unidos, visión común predominantemente optimista sobre la globalización y una visión común sobre la integración y el regionalismo basado en el regionalismo abierto (Bernal-Meza, 2012c, 2013), las relaciones internacionales de los países latinoamericanos estaban marcadas por las diferencias en torno a cuatro temas centrales: la visión sobre la globalización, el grado de apertura económica, las relaciones con Estados Unidos y los paradigmas de regionalismo e integración (Bernal-Meza, 2012c; Bernal-Meza y 
Christensen, 2012); es decir, sus diferencias se centraban justamente sobre aquellos temas sobre los cuales habían sentado coincidencias solo una década antes.

El tiempo presente nos encuentra ante un cambio de época. La reconciliación diplomática entre Estados Unidos y Cuba y la posterior visita de Obama a La Habana constituyeron un quiebre -político, ideológico, eidético y de paradigmas- con respecto al pasado que, siguiendo la argumentación de Hobsbawm (2007) sobre los períodos históricos del siglo $\mathrm{XX}$, marcaron un "cambio de época" en las relaciones internacionales hemisféricas. Este hecho fue la expresión de la concepción social del poder que tuvo Obama (Santa Cruz, 2017), que quedó de manifiesto con el restablecimiento de relaciones diplomáticas con Cuba Este cambio dio inicio a una reconfiguración cuyas tendencias estarán determinadas por los recambios políticos de gobierno en distintos países de América Latina pero, fundamentalmente, por el proceso de transición hacia un nuevo orden de relaciones hemisféricas y mundiales que implica la política internacional del presidente Donald Trump. En este contexto, lo nuevo, que está representado por el "cambio de época", forma parte de los rasgos sobresalientes de aquello que derivará de la política que está siguiendo el nuevo presidente norteamericano y que constituirá parte estructural del nuevo marco de relacionamiento hemisférico y mundial.

A pesar del hecho que las decisiones de Trump respecto de los acuerdos Obama-Castro y que las políticas que el anterior presidente estadounidense estaba llevando a cabo fueron detenidas en parte y condicionadas por el actual presidente, esto - a mi juicio- no modifica el sentido del "cambio de época", porque sus anuncios no modifican los aspectos singulares que marcaron el cambio: las embajadas siguen abiertas, los vuelos y el tráfico de cruceros no fueron prohibidos y tampoco se trabó el envío de remesas, como tampoco se restauró la política "pies mojados, pies secos" $12^{1}$ que Obama había desactivado (Cantelmi, 16 de junio de 2017). Se trata de un cambio simbólico, de narrativa, que no afectará el curso de la apertura iniciada por Obama (Lugones, 17 de junio de 2017).

Pero el contexto internacional y hemisférico de incertidumbre está identificado por el retorno de Estados Unidos al proteccionismo y el unilateralismo y una visión antiglobalización, asociada a un discurso nacionalista, xenófobo y abiertamente antilatinoamericano, identificado en el agravio al pueblo mexicano y la construcción del muro en la frontera entre ambos países. Trump ha cambiado el eje del conflicto: desde La Habana hacia la frontera norte de México.

Como señala Santa Cruz (2017), la concepción del poder ha sido un factor clave en el desempeño de Estados Unidos como país hegemónico, desde el fin de la Segunda Guerra Mundial, y el recurso al multilateralismo o el unilateralismo, por parte de Washington, se explica en mayor medida por cómo entiende la respectiva Presidencia el ejercicio del poder

1 Legislación que daba refugio sin visado en Estados Unidos a cualquier balsero cubano que llegara a tocar las costas de ese país (pies secos), beneficio que no cubría a quienes quedaban varados en el mar (pies mojados). 
y no tanto por una hegemonía medida en términos exclusivamente materiales. La concepción del poder tiene efectos importantes sobre su aplicación. En el caso de Estados Unidos, la concepción de Trump impacta directamente en la manera en que Washington ejerce su hegemonía y la propensión a adoptar políticas unilaterales, como se ha visto frente al Acuerdo de París, la negociación del TTP, las amenazas sobre el destino del TLCAN, que llevaron a la renegociación de los acuerdos con México y Canadá, y las negociaciones comerciales entre Estados Unidos y la Unión Europea. Apelando a Guzzini (2013), Santa Cruz señala que la hipótesis implícita de la mayoría de los observadores es que la preponderancia actual de Estados Unidos en los asuntos mundiales explica su uso creciente de políticas unilaterales, cuestión en la que coinciden Malone y Khong (2003). En particular, cuando quien ejerce la presidencia, consciente de los mayores recursos de poder material que acumula la potencia, en relación con sus aliados y adversarios, explica en gran parte la preferencia por el unilateralismo. Así, parafraseando la argumentación de Santa Cruz (2017), al analizar la hegemonía ejercida por Bush hijo, podemos afirmar que Donald Trump está ejerciendo hoy una hegemonía pírrica.

Por su parte, el escenario regional está marcado por fuertes incertidumbres, como consecuencia de los cambios político-gubernamentales, que ponen en evidencia el retroceso de los "progresismos" y "populismos" que vinieron para recomponer la situación de crisis generalizada provocada por una década de políticas neoliberales. La reconfiguración del orden hemisférico produce respuestas regionales que se evidencian en la variedad de alianzas, nuevos ejes de países y cambios en el escenario del regionalismo.

El "cambio de época" está evolucionando, a nivel sistémico y también en América Latina. A nivel sistémico, con la profundización del unilateralismo y el proteccionismo por parte de Estados Unidos y por la firma del TPP11 (CPTPP, por sus siglas en inglés), sin la participación de Washington y que desafía el proteccionismo del presidente Trump, porque el acuerdo crea una nueva área de regionalismo en la economía mundial. También por el creciente papel de China en la economía política internacional y su creciente acercamiento a América Latina.

\section{El punto de partida: el retorno al proteccionismo y el unilateralismo de los Estados Unidos}

La crisis de la globalización y del orden liberal, en tanto crisis de hegemonía, está expresada en la presidencia de Donald Trump, siendo el primer presidente norteamericano que desde los años treinta cuestiona abiertamente el internacionalismo liberal a través de una agresiva política de revisión del multilateralismo vigente y, en particular, de las normas comerciales en las que se sustenta la globalización, y de las instituciones y reglas en las que se ha basado el vínculo noratlántico, económico y de seguridad. Esa crisis de hegemonía tiene dimensiones múltiples y daría fin a la etapa de la postguerra fría, dominada por el avance de la democracia y el internacionalismo liberal y por la globalización económica (Sanahuja, 2018). 
En el contexto global, pocos momentos de los últimos 30 años podrían asemejarse a estos tiempos por la dimensión de la incertidumbre. Con Trump hay un discurso antiglobalización, xenófobo, de extremismo nacionalista, de ruptura y anticivilización universal, que se inscribe en el contexto hemisférico de ese cambio de época, porque implica dos políticas opuestas a las tendencias del multilateralismo; políticas que son contrarias a la negociación, la mayor participación de un gran número de Estados en la concertación de decisiones comunes y la gestión político-diplomática de los conflictos.

La indiscutible hegemonía estadounidense, posterior a la Segunda Guerra Mundial, no estuvo acompañada por la predominancia del unilateralismo; por el contrario, Estados Unidos impulsó la creación de las mayores instancias multilaterales de gobernabilidad mundial: Bretton Wood -FMI, Banco Mundial, OIC-, sistema de Naciones Unidas, el Acuerdo General del GATT, etc. Aun así, históricamente, los Estados Unidos han oscilado entre el multilateralismo y el unilateralismo (Bernal-Meza, 2005; Malone y Khong, 2003; Santa Cruz, 2017; Stewart y Forman, 2002). En este sentido, la política seguida por Trump no representa una ruptura con la tradición norteamericana, porque no hubo históricamente una línea única de comportamiento internacional y del ejercicio del poder, pero sí respecto de ciertas tendencias favorables al tratamiento multilateral de las agendas, que había caracterizado a los gobiernos demócratas de Clinton y Obama. Durante esta última presidencia, los Estados Unidos regresaron a la política multilateral que había sido abandonada por su antecesor (Bush hijo) y la hegemonía fue ejercida por la administración Obama a través del multilateralismo (Santa Cruz, 2017).

Un retorno cada vez más excluyente del unilateralismo provoca un fortalecimiento de la política bilateral y un deterioro de las negociaciones internacionales en todas las agendas globales, tal como se ha advertido en el abandono del Acuerdo de París y del TTP, que implicaron frenar el avance en el control y la regulación del deterioro medioambiental y del multilateralismo comercial, regulación (medioambiental) y liberalización (comercial) que son apoyadas por el pensamiento liberal sobre la globalización y el ejercicio social del poder.

En opinión de la cancillería chilena (Morales, 9 de marzo de 2018), la firma del TPP11 (CPTPP), establecerá un nuevo estándar para otros acuerdos de integración económica regional, e incluso para futuras negociaciones en la Organización Mundial del Comercio y en el Foro de Cooperación Económica Asia-Pacífico. El acuerdo pone un freno, en el ámbito del comercio, a la política proteccionista de Trump. Once países -Japón, Canadá, Australia, México, Chile, Brunei, Nueva Zelanda, Perú, Singapur, Malasia y Vietnam- firmaron este gran acuerdo, una de cuyas características es que algunos de sus miembros son parte de los principales socios internacionales de Estados Unidos y que con su decisión han marcado también distancia respecto de la política comercial unilateral de Washington.

A nivel internacional, debe señalarse el liderazgo de la política exterior chilena que, en ejercicio del Presidencia Pro témpore de la Alianza del Pacífico, logró reflotar el 
acuerdo de liberalización comercial del Asia-Pacífico (TTP) y sustituir el liderazgo que China se había propuesto en el área Asia-Pacífico y que era parte de su estrategia de promoción y expansión de la globalización capitalista, reemplazando a un Estados Unidos proteccionista y aislacionista.

\section{A nivel hemisférico}

Se advierte la ausencia de una política definida de la administración Trump en relación con América Latina. ${ }^{2}$ No hay claridad respecto de la política a seguir sobre la defensa de los sistemas democráticos y los derechos humanos - con la excepción de las duras posiciones y medidas económicas y políticas norteamericanas frente al gobierno de Nicolás Maduro-, como también dudas acerca de la continuidad de la ayuda al desarrollo por vía de políticas comerciales flexibles. Argentina, Brasil, México, son los países que se han visto más afectados por las decisiones comerciales norteamericanas, países a los que Washington ha estado aplicando medidas proteccionistas a productos industriales (acero, aluminio), energéticos (biocombustibles) y productos agrícolas (carne vacuna).

Por otra parte, mientras por un lado se refuerza la política agresiva hacia México, con la construcción del muro en la frontera y se aplican medidas en contra de los inmigrantes latinos en condición irregular, por otra parte es la primera vez - desde que los propios Estados Unidos impulsaron la ronda de "Cumbres de las Américas"- que un presidente norteamericano faltó a la cita hemisférica (realizada en Lima, 13 y 14 de abril de 2018), evidenciando con ello el poco interés que América Latina tiene en la agenda internacional del presidente estadounidense. La prensa internacional ha tomado nota del recelo y la apatía que provoca y manifiesta el tipo de relación que Trump ha mantenido con América Latina (Lissardy, 26 de abril de 2018). No obstante, altos funcionarios, como el vicepresidente Mike Pence -quien a la fecha ha realizado tres giras a la región- y el secretario de Estado, Mike Pompeo (Voa Noticias, 1 de diciembre de 2018), ${ }^{3}$ visitaron varios países de América Central y Sudamérica. A pesar de ello, las declaraciones de ambos funcionarios han contrastado con las opiniones de Trump, respecto de las opciones frente al gobierno de Nicolás Maduro e, incluso, con respecto al proteccionismo: mientras el presidente Trump denunciaba el Tratado de Asociación Transpacífico (TPP, por su siglas en inglés) -el acuerdo estrella de Obama para la región Asia-Pacífico- y amenazaba con el uso unilateral de la fuerza en Venezuela, el secretario de Estado manifestaba tener posiciones distintas (Cué, 15 de agosto de 2017). ${ }^{4}$

2 Afirmación basada en la declaración del presidente de Chile, Sebastián Piñera, en entrevista con The Washington Post; ver Romero (22 de marzo de 2018).

3 Las preocupaciones de la agenda latinoamericana de Pompeo han girado en relación con China, manifestando la preocupación de Estados Unidos por la creciente presencia económica y financiera del gigante asiático en la región, y la situación de Venezuela.

4 La preocupación principal de Pence ha estado relacionada con la promoción del libre comercio y el interés de que Estados Unidos se mantuviera dentro del TTP. Posteriormente y expresando aquí la preocupación del presidente Trump, su atención se ha centrado en la situación política, interna y externa, de Venezuela. En su primer viaje (13-17 


\section{Los cambios en el escenario latinoamericano}

Como señala Sanahuja (2018), “América Latina, tras dejar atrás la crisis económica global y el ciclo favorable de las materias primas, parece descubrir que con el cambio de siglo se ha imbricado mucho más profundamente en la globalización" (p. 37). Lo ha hecho de la mano tanto de la continuidad de gobiernos liberales y promercado (Chile, Colombia), como de los nuevos gobiernos (Argentina, Perú) y de Brasil, luego de las complejas transiciones y conflictos políticos.

El regionalismo latinoamericano ha sufrido el impacto del despliegue del regionalismo posliberal (Sanahuja, 2012; Serbin, 2012) o poshegemónico (Riggirozzi y Tussie, 2012; Briceño-Ruiz y Morales, 2017), como instrumentos estratégicos en la definición de nuevos modelos de desarrollo (Serbin, 2018). Como señala este autor,

Paradójicamente, mientras la narrativa del regionalismo post-hegemónico o postliberal, privilegió la concertación política inter-gubernamental, el rol del Estado sobre el mercado, y la búsqueda de nuevos modelos de desarrollo, la nueva coyuntura regional, junto con las debilidades antes mencionadas y en el marco de la persistencia de las relaciones asimétricas de la región con la mayoría de los actores más poderosos del orden global emergente, tiende a privilegiar la restauración de políticas neoliberales y un debilitamiento del estatismo, retomando los valores de la gobernanza global impuesta por Occidente. (Serbin, 2018, pp. 23-24)

Hay así un avance del regionalismo liberal (regionalismo abierto), expresado en la atracción que está ejerciendo la Alianza del Pacífico (AP) en el entorno latinoamericano y el papel que cumplió la AP, en particular por el liderazgo de Chile -el país que ha sido la vanguardia hemisférica del liberalismo comercial- en la concreción del TPP11. Al mismo tiempo, se observa un profundo retroceso del regionalismo anticapitalista (ALBA) y el inmovilismo en que se mantiene el Mercado Común del Sur (MERCOSUR), que no ha logrado superar la condición de unión aduanera imperfecta.

Los gobiernos llamados populares, populistas o progresistas, surgidos a partir del inicio del siglo XXI como impugnaciones o respuestas al neoliberalismo, no identificaron su praxis política internacional como actores antiglobalización. Por el contrario, aceptaron el beneficio del precio global de los commodities y los recursos naturales, y orientaron tanto la economía como la ampliación del poder estatal, intentando capturar algo del beneficio producido por la explotación del petróleo, la minería y los cereales a través de dinámicas regulatorias (De Gori, Gómez y Ester, 2017, p. 18). Es importante en este sentido señalar que ninguno de estos gobiernos modificó o transitó el camino hacia la transformación de la

de agosto de 2017), el vicepresidente norteamericano visitó Colombia, Argentina, Chile y Panamá, hacia donde llevó la preocupación norteamericana y la oposición al gobierno de Nicolás Maduro. Pence ha tomado distancia del presidente Trump respecto de las opciones militares unilaterales contra Maduro. En Buenos Aires señaló que "cualquier intervención en Venezuela será consensuada con Latinoamérica" (Cué, 15 de agosto de 2017). 
estructura productiva de inserción internacional y se especializaron cada vez más en la exportación de bienes primarios. En particular $-\mathrm{y}$ esa sigue siendo la tendencia-, la especialización primaria que caracteriza a las economías al sur de México ha conducido a un nuevo ciclo de relaciones centro-periferia con China (Bernal-Meza, 2017a, 2017b, 2017c, 2016a, 2012a, 2012b; CEPAL, 2015; Ellis, 2009; Guelar, 2013; Oviedo, 2012a, 2012b, 2014; Ortiz y Dussel, 2016; Pastrana y Gehring, 2017; Sevares, 2015), que se aceleró y profundizó justamente en coincidencia con el inicio del nuevo siglo. Paradójicamente, convergieron la primerización y reprimerización de las economías latinoamericanas bajo los gobiernos populares-progresistas, con la nueva dependencia de la economía china.

Adicionalmente, el impacto de este proceso se ha hecho sentir negativamente sobre los procesos de gobernanza e integración latinoamericana. Como afirma un especialista el análisis de los respectivos documentos y bloques comerciales refleja que China, en efecto, ha trastocado, en los últimos quince años, en forma significativa, el proceso de integración comercial, ha afectado tanto los diferentes procesos de integración comercial -a diversos niveles como a sus principales socios comerciales, en particular a los miembros de los distintos bloques comerciales [...]. (Dussel Peters, 2016, p. 11)

El retroceso de los gobiernos "populares", "populistas", "progresistas" o de (centro) izquierda -según el perfil político de los analistas que se citen- y el regreso de gobiernos liberales o de centro-derecha, como ha ocurrido en Argentina, Brasil (en este caso por la destitución de Dilma Rousseff), Chile, Ecuador ${ }^{5}$ y Perú (por elección y luego por destitución), impactaron también sobre la vigencia de los respectivos acuerdos de integración en los cuales estos países estaban involucrados. Se ha fortalecido la AP -hecho que se expresa en su papel de liderazgo en el salvataje del TTP, como a través de la atracción ejercida hacia nuevos países que aspiran a ingresar como observadores (cuyo más importante nuevo interesado es Corea del Sur)-, en desmedro del retroceso profundo de ALBA y del inmovilismo o "amesetamiento" (Gajate, 2016) del MERCOSUR -que enfrenta dificultades en las dimensiones económica y comercial, cuya respuesta ha parecido estar más cerca de una perspectiva más política y estratégica y menos ocupado en una agenda social-, el cual trata de remontar el liderazgo del presidente Macri intentando reflotar las negociaciones para un acuerdo de libre comercio entre el bloque subregional y la Unión Europea.

Pero hay otros elementos que marcan este cambio de época en América Latina y que desafían las certidumbres de la década precedente, como la pérdida del liderazgo regional del Brasil, lugar que está siendo ocupando en forma creciente por el presidente argentino Mauricio Macri. Este liderazgo se advierte respecto del regionalismo, buscando la convergencia entre el MERCOSUR y la Alianza del Pacífico, el impulso a retomar con

5 Lo que queremos señalar aquí es que Ecuador, bajo el gobierno de Lenin Moreno, se alejó del eje Venezuela-Cuba y se fue transformando en uno de los principales críticos del gobierno de Nicolás Maduro. Con ello tomó una importante distancia respecto del período de gobierno de Correa, entre 2007 y 2017, que hizo de Chávez y luego de Maduro su más estrecho aliado en la región. 
prioridad la búsqueda de un ALC entre MERCOSUR y la UE y por sus posiciones en defensa de los sistemas políticos democráticos en la región (particularmente frente a Venezuela), así como el fortalecimiento de la proyección regional e internacional de la Alianza del Pacífico. No obstante, la profunda crisis económica y financiera interna que se agudizó durante 2018 y lo que va de 2019, ha obligado al presidente Macri a volcarse a los problemas internos y disminuir su activismo internacional.

En este contexto, dos tendencias de fuerza aparecen en el horizonte: por un lado, el inmovilismo regional y la ausencia de liderazgos políticos por parte de los agrupamientos regionales y subregionales (CELAC, MERCOSUR, ALBA); por otro, el silencio frente a Washington de aquellos países que no arrastran una historia reciente de conflictos con la potencia, con la sola excepción de Argentina. Frente a la situación de desprecio y malos tratos de Trump, más allá de las expresiones solidarias de Venezuela y Bolivia (que deberíamos considerar casi "naturales", vistos sus respectivos enfrentamientos con los últimos gobiernos norteamericanos), el presidente que expresó con gran fuerza su solidaridad con México ha sido Macri. Esta situación llama la atención sobre un hecho: el divorcio que existe entre los aspectos económicos y los políticos que giran en torno a la toma de decisiones dentro del único modelo de regionalismo que se acerca al ideario económico-político norteamericano: la Alianza del Pacífico.

Argentina es un país que está de regreso a sus intereses regionales de una manera más amplia y está dando muestras de estar buscando un nuevo posicionamiento internacional, que en la oposición político-ideológica ocupa el vacío dejado por la conflictiva introspección del gobierno de Venezuela y por la crisis que envolvió al sistema político brasileño. En este contexto, el único bloque que manifiesta una dinámica de proyección internacional es la AP, que podría tener la posibilidad de constituirse en un ambicioso proyecto de desarrollo político y de consolidación como bloque de expresión regional. Sin embargo, también se podría afirmar que la AP es solo un instrumento para proyectar regional e internacionalmente su filosofía de economía política liberal. Esta connotación se aprecia al comprobar que la política exterior chilena -que ha manifestado en algunos momentos su disposición a cierto liderazgo de "concepto" (Maira, 2010; Fuentes, 2010) ${ }^{6}$ no tiene definiciones "políticas" sobre qué hacer con la AP. Llama la atención, en este sentido, que la posición de la cancillería chilena, en relación con un eventual interés que Washington habría manifestado de regresar al TTP (o integrarse al TTP11), la haya definido públicamente la Dirección General de Relaciones Económicas Internacionales y no su área política (Soy Chile, 12 de abril de 2018; Gattavara, 27 de enero de 2018; Publimetro, 13 de abril de 2018).

Sin embargo, si la AP quiere ser convertida en el nuevo bloque de coordinación económica y política de América Latina -beneficiándose de la cercanía de Argentina y Brasil y del

6 Definición acuñada por el entonces canciller del Brasil, Celso Lafer, para referirse a Chile que también le había conferido Collin Powell. Ver Maira (2010) y Fuentes (2010). 
interés en la AP que expresan sus gobiernos, los miembros de la AP deben estar dispuestos al liderazgo, cosa que no se advierte en el escenario regional inmediato. Para su proyección global como bloque, la AP requiere de un escenario internacional de apertura comercial, de multilateralismo y creciente desregulación. Un escenario de proteccionismo, nacionalismo económico y retorno a las políticas unilaterales por parte de Estados Unidos afectará el futuro de la AP. Mirando en perspectiva, la AP está transitando un proceso que ya advertimos con MERCOSUR, UNASUR y CELAC. Se comparte así la visión de Ojeda (2017), quien señala que ninguno de los esquemas y plataformas de regionalismo e integración ha conseguido aún consolidar un proyecto político claramente articulado para gestionar con eficacia y armonías la planificación y ejecución de la integración, pero, sobre todo, ninguno ha conseguido frenar la proliferación de esquemas subregionales.

\section{Politicas exteriores: rupturas y continuidades frente al "cambio de época"}

Del estado de situación precedente podemos derivar algunas tendencias que identifican las interpretaciones conceptuales de algunas de las políticas exteriores de la región y, en especial, los nuevos aportes. La crisis política en Brasil ha llevado consigo la pérdida de liderazgo en Sudamérica y el deterioro de su posición en la economía y la política mundiales, con impactos en su presencia en BRICS, que constituye el más importante conglomerado contemporáneo de potencias emergentes. El deterioro, que venía desde el gobierno de Dilma Rousseff, se había manifestado en un abandono relativo de la importancia que Lula le había asignado a la región (Cervo y Lessa, 2014; Flemes y Saraiva, 2014). La política exterior de Lula da Silva, el primer gobierno del Partido de los Trabajadores (PT) en la historia política brasileña, inició a comienzos de 2003 una estrategia regional orientada a la revisión de las instituciones internacionales surgidas bajo la hegemonía norteamericana y con una política proactiva en los foros multilaterales intentó presentarse como representante de los países del Sur y especialmente de Sudamérica. Para ello desarrolló una red de coaliciones internacionales y regionales e impulsó nuevos instrumentos de gobernanza regional -Comunidad Sudamericana de Naciones (CSN), UNASUR, CELAC (Bernal-Meza, 2015c; Saraiva, 2016)- que, luego de su segundo gobierno, dejó como herencia a su sucesora, Dilma Rousseff. Esta política se identificó con el liderazgo ${ }^{7}$ regional.

Sin embargo, desde los dos últimos años del segundo mandato de Lula las condiciones internacionales e internas de Brasil se modificaron negativamente. Se produjo un deterioro del país en el contexto de la economía política internacional derivado de sus fragilidades externas e internas. Fuentes estadísticas sobre la evolución del comercio exterior ponen de relevancia ese retroceso:

7 Entendemos aquí el liderazgo según lo sintetiza Saraiva (2016), como la capacidad del país de influir sobre los demás para que estos adopten un determinado comportamiento. 
Tabla $N^{\circ}$ 1: Evolución del comercio exterior de Brasil (2013-2017)

\begin{tabular}{|c|c|c|c|c|c|}
\hline $\begin{array}{c}\text { Indicadores de comercio } \\
\text { exterior }\end{array}$ & 2013 & 2014 & 2015 & 2016 & 2017 \\
\hline $\begin{array}{l}\text { Importación de bienes } \\
\text { (millones de USD) }\end{array}$ & 250.556 & 239.152 & 178.798 & 143.474 & 157.476 \\
\hline $\begin{array}{l}\text { Exportación de bienes } \\
\text { (millones de USD) }\end{array}$ & 242.034 & 225.101 & 191.134 & 185.280 & 217.769 \\
\hline $\begin{array}{l}\text { Importación de servicios } \\
\text { (millones de USD) }\end{array}$ & 81.053 & 85.916 & 68.921 & 63.750 & 66.293 \\
\hline $\begin{array}{l}\text { Exportación de servicios } \\
\text { (millones de USD) }\end{array}$ & 36.482 & 39.047 & 32.989 & 33.300 & 33.677 \\
\hline $\begin{array}{l}\text { Importación de bienes y } \\
\text { servicios (crecimiento } \\
\text { anual en \%) }\end{array}$ & 7,2 & $-1,9$ & $-14,2$ & $-10,2$ & 5,0 \\
\hline $\begin{array}{l}\text { Exportación de bienes y } \\
\text { servicios (crecimiento } \\
\text { anual en \%) }\end{array}$ & 2,4 & $-1,1$ & 6,8 & 1,9 & 5,2 \\
\hline $\begin{array}{l}\text { Importación de bienes y } \\
\text { servicios (en \% del PIB) }\end{array}$ & 13,9 & 13,7 & 14,1 & 12,1 & 11,6 \\
\hline $\begin{array}{l}\text { Exportación de bienes y } \\
\text { servicios (en \% del PIB) }\end{array}$ & 11,6 & 11,0 & 12,9 & 12,5 & 12,6 \\
\hline $\begin{array}{l}\text { Balanza comercial } \\
\text { (millones de USD) }\end{array}$ & 389 & -6.629 & 17.670 & 45.037 & 64.028 \\
\hline $\begin{array}{l}\text { Balanza comercial } \\
\text { (incluyendo servicios) } \\
\text { (millones de USD) }\end{array}$ & -45.984 & -54.736 & -19.276 & 14.590 & 30.178 \\
\hline $\begin{array}{c}\text { Comercio exterior (en el } \\
\% \text { del PIB) }\end{array}$ & 25,6 & 24,7 & 27,0 & 24,6 & 24,1 \\
\hline
\end{tabular}

Fuente: WTO-World Trade Organization; World Bank, últimos datos disponibles.

Según estudios del Banco Santander, basado en datos de la Organización Mundial de Comercio la balanza comercial de Brasil es estructuralmente excedentaria, pero ha tenido una tendencia a la baja estos últimos años, debido a la disminución de los precios de las materias primas, el alza de las importaciones de energía y una menor competitividad de los productos brasileños. La balanza de cuentas actual de Brasil representó -0,6\% del PIB en 2017, en comparación con -1,3\% en 2016. De 2013 a 2015, Brasil marcó déficits comerciales, pero la balance ha repuntado desde mediados de 2016, llegando según las estimaciones a 8.000 millones USD a fines de 2017. (Banco Santander, 2019) 
Internacionalmente, el gobierno de Lula había impulsado la creación de alianzas de potencias medias o "emergentes", con el fin de posicionarlas como una alternativa al poder de las potencias occidentales en el marco de la economía política internacional, respecto del orden político y económico global, en particular BRICS (Stuenkel, 2015), mientras que en la región impulsaba la creación de la Comunidad Sudamericana de Naciones -luego UNASUR- y el Consejo de Defensa Suramericano, como ámbitos de cooperación económica, política y de seguridad, perdieron interés en la agenda de Dilma. Brasil fue perdiendo protagonismo, tanto en la política global como en la regional y sus movimientos adquirieron un carácter reactivo (Saraiva, 2016) que contrastó con el carácter proactivo, de iniciativas, de los dos gobiernos de Lula.

Por su parte, la reproducción al interior de BRICS de una relación centro-periferia, en el comercio entre China y Brasil, dado el proceso de primerización de las exportaciones brasileñas y la desilusión de no haber alcanzado con China una relación de pares, que Beijing no lo hubiera asociado a su política mundial, hicieron que la presencia de Brasil en BRICS y su relación Norte-Sur con China, llevaron a que al interior de BRICS se generaran condiciones de debilidad que afectaron sus capacidades como poder emergente y líder del "Segundo Mundo" (Christensen y Bernal-Meza, 2014) ${ }^{8}$ en la construcción del nuevo orden mundial. El deterioro de su posición en la economía (IPEC, 2015) ${ }^{9}$ y la política mundiales marcan un fracaso del soft power y el soft balancing, que Brasil impulsó como su paradigma de política internacional y hemisférica (Flemes, 2012a).

En cuanto a México, el abandono del paradigma de potencia media, como consecuencia de la política de alianza e integración con Estados Unidos (Bernal-Meza, 2009), seguida y fortalecida bajo el gobierno liberal de Fox (Rubio y Kaufman, 2004), lo alejó del horizonte latinoamericano y, en especial, del sudamericano. Esta fue una situación que benefició a Brasil para posicionarse con el liderazgo sudamericano desde la región al mundo (BernalMeza y Bizzozero, 2014). Felipe Calderón buscó reencauzar las relaciones de México con América Latina -y particularmente con Sudamérica- con dos iniciativas: impulsó la creación de CELAC y lo incorporó a la Alianza del Pacífico. Si bien CELAC constituyó un esfuerzo por recomponer las deterioradas relaciones con la región y en particular con Cuba, Venezuela y Bolivia, la integración a la Alianza del Pacífico significó inyectar en esta las visiones de políticas económicas liberales, libre mercado, apertura y cercanía con Estados Unidos, propias de la perspectiva de economía política que México ha seguido desde

8 Según Christensen y Bernal-Meza (2014), la evolución del sistema internacional desde las décadas de 1970-1980 y la aparición de coaliciones y poderes regionales, como los BRICS, dieron por resultado la configuración de un orden sistémico caracterizado por la emergencia de un segundo mundo. Los autores señalan que "Does the Second World refer to a condition or to a counter position to a First World and a Third World, or does it refer to a position in the structure of the world system" (p. 37-38). Khanna (2012) ha definido como el "Segundo mundo" aquello representado por macrorregiones que no forman un espacio geográfico que está unificado, sino que está formado por espacios geográficos separados: Europa del Este, Asia Central, América Latina y Oriente Medio. Estas son regiones que concentran algún nivel de poder como economías emergentes.

9 La participación del PBI brasileño en el PBI mundial, que en 1987 había sido del 4,2\%, pasó en 2006 a ser del 3\%, aumentando al 3,8\% en 2010, al fin del mandato de Lula. Luego se iniciaría una nueva fase de caída hasta 3\% en 2014, con proyecciones de 2,89\% para 2015 y de 2,82\% para 2016; las cifras más bajas desde 1980. Ver IPEC (2015).

96 Si Somos Americanos. Revista de Estudios Transfronterizos 
comienzos de los años noventa. Pero a ello le agregó la predisposición a competir con Brasil por el liderazgo sudamericano (Bernal-Meza, 2015), pues en los hechos, al compartir una alianza con los tres países sudamericanos que nunca se incorporaron como socios plenos del MERCOSUR -Chile, Perú, Colombia-, completaba un eje de articulación latinoamericana con Washington y generaba la percepción de estar provocando una fragmentación de la región. El ascenso de López Obrador a la presidencia de México, si bien ha mantenido a su país dentro de la Alianza del Pacífico, ha manifestado un claro apoyo a Nicolás Maduro, bajo el argumento de que su política exterior se sostiene en el respeto a la tradición de la "doctrina Estrada", que declara su oposición a que el país decida por sí si el gobierno de un tercer Estado extranjero es legítimo o ilegítimo, argumentación que está en contra de lo que opina el nuevo gobierno de Bolsonaro, ${ }^{10}$ con lo cual está surgiendo un claro contrapunto en relación con la situación de un país cuya ubicación geográfica está en Sudamérica (Giacalone, 2015), tradicional subregión de liderazgo brasileño. Asimismo, la mayor presencia de México en Sudamérica -por vía de la Alianza del Pacífico y sus posiciones frente a Venezuela- puede alentar a otros gobiernos sudamericanos a asumir posiciones independientes frente a Brasil, debilitando más su liderazgo.

El presidente Bolsonaro, a partir de su asunción, en enero de 2019, produjo cinco importantes cambios en la política exterior sudamericana del Brasil, en relación con el período 2003-2018: retornó al país a una relación cercana a la política exterior norteamericana; quitó su apoyo y luego retiró al país de la UNASUR; quitó el respaldo político al gobierno venezolano, identificándolo como la principal amenaza para la seguridad y estabilidad de la región; puso al MERCOSUR como un tema no prioritario de la agenda y redujo el perfil de prioridad que Brasilia tradicionalmente -desde 1985- le asignaba a Buenos Aires (Teletrece, 29 de octubre de 2018). ${ }^{11}$

Argentina, luego del triunfo del presidente Mauricio Macri, modificó sustancialmente su política exterior. Se alejó del eje Venezuela-Ecuador-Bolivia, acercando posiciones a Chile y Brasil y adoptando una visión de regionalismo que ha propiciado la complementación entre el MERCOSUR y la AP. Un elemento adicional lo constituye la recomposición de las relaciones con Estados Unidos, objetivo que acercaría más a Argentina a los países de la AP. Macri recibió al presidente Obama en la primera visita que este hizo a la Argentina en sus dos presidencias y Macri retribuyó la misma una semana después (23 y 24 de marzo de 2016; 31 de marzo y 1 de abril de 2016, respectivamente), ${ }^{12}$ ocasión de intercambios presidenciales que no tuvo precedentes en los últimos 20 años, si no consideramos la visita del presidente Busch Jr. en noviembre de 2005, que fue en el marco de la Cumbre de las Américas en Mar del Plata, pero que no constituyó una visita oficial a la Argentina.

10 También el Grupo de Lima.

11 Desde 1985 había existido una tradición presidencial: el primer viaje internacional de un presidente brasileño era a Buenos Aires. Bolsonaro declaró que su primer viaje oficial al exterior sería a Chile.

12 La visita a Washington del presidente argentino se dio en el marco de la cumbre nuclear que organizó el presidente Barack Obama. 
Un elemento que toma particular relevancia, asociado a la búsqueda de un nuevo relacionamiento con Estados Unidos, fue la confirmación que expresó la entonces canciller argentina, acerca de sus conversaciones en el MERCOSUR, sobre la posibilidad de negociar un Tratado de Libre Comercio con los Estados Unidos (TLC) (Clarín, 15 de marzo de 2016). La búsqueda de buenas relaciones con Estados Unidos ha continuado bajo la presidencia de Trump. Estos dos factores - buenas relaciones con Estados Unidos y acuerdos de libre comercio con dicha potencia- son parte importante de las coincidencias que tienen actualmente los cuatro países miembros de la AP.

Chile y Colombia representan el ascenso de dos potencias secundarias que se reconocen a sí mismas como tales (Ardila, 2013; Betancourt, 2013; Flemes, 2012b; Maira, 2015; Pastrana y Vera, 2013). Lo novedoso de la reciente política exterior de Colombia es su apertura al Pacífico y el fortalecimiento de los vínculos con México, Chile y Perú, con los que comparte buenas relaciones (no conflictivas, en ese sentido), con Estados Unidos y enfoques de economía política liberal, aunque la apertura al Asia-Pacífico es una estrategia de aproximación que Colombia solo empezó a desarrollar con la llegada al gobierno del presidente Santos (Pastrana, Betancourt y Castro, 2014).

El pensamiento en asuntos internacionales y política exterior, en ambos países, gobernados por coaliciones liberales, se ha caracterizado por la variable continuidad-continuidad en sus líneas eidéticas centrales, con prevalencia de las relaciones con Estados Unidos, con una similar predominancia de una visión "economicista" de la política exterior que ha acercado a ambos países. Sin embargo, respecto de Venezuela, ambos países iniciaron, a mediados del año 2018, una campaña internacional en contra de Maduro, que sacó a sus respectivas políticas exteriores de una línea anteriormente pragmática basada en la búsqueda de ganancias económicas (Artaza y Ross, 2012, 2015; Briones y Dockendorff, 2015; Jost, 2013; Pastrana, Castro y González, 2017), y las embarcó en una campaña fuertemente ideológica y política en defensa de la democracia, acusando a la presidencia de Venezuela de ser un gobierno antidemocrático y dictatorial.

En cuanto a Venezuela, mientras se profundiza la crisis política, económica y social interna, el país se ha deslizado a una situación de fuerte aislamiento en la región. La promoción de iniciativas y las aspiraciones de liderazgo venezolano, bajo la conducción de Chávez, llegarían a su fin con su desaparición física y la asunción de Maduro. El activismo internacional de Venezuela no continuó bajo Maduro en la misma dimensión global ni regional. Las nuevas ideas incorporadas, sostenidas en el pensamiento de Gullo (2010) basado en la insubordinación fundante, no permitieron la expansión de la política exterior hacia otros horizontes, ni tampoco logró mantener la amplia red de vínculos internacionales forjados por Chávez (Bernal-Meza, 2017d; Romero y Mijares, 2016). La AP resultaría a la postre el actor clave del aislamiento regional de Venezuela, no porque sus miembros se lo propusieran, sino porque cambiaron los gobiernos y las alianzas gubernamentales en otros países que modificaron sus visiones respecto de 
Venezuela y la AP. Los gobiernos de Argentina (Cristina Fernández), Brasil (Rousseff) y Uruguay (Mujica), que le habían sido críticos a la AP y favorables a Venezuela, ahora, con Macri, Temer y Vázquez, le eran receptivos (Bernal-Meza, 2017d) y críticos con Venezuela, respectivamente.

\section{Renovación y actualización conceptual en la política exterior chilena}

La más reciente renovación -o más bien "actualización"- conceptual de fundamentos de política exterior se ha producido en Chile. Durante su última gestión presidencial, Michelle Bachelet incorporó en su política exterior un nuevo concepto para justificar y hacer más comprensible su pensamiento en asuntos internacionales. Este nuevo concepto fue el de "convergencia en la diversidad". Según la presidenta, el concepto fue planteado originalmente dirigido a la región, como fundamento para la sostener la cooperación entre la AP y el MERCOSUR, pero luego fue extendido con una pretensión de universalidad. Así lo manifestó:

este concepto es mucho más que una definición pragmática para navegar en el cambiante escenario latinoamericano. Es un concepto que pretende una validez y una permanencia más amplia, pues se funda en nuestra lectura de las dinámicas globales de las sociedades y de sus relaciones internacionales, proponiendo una mirada cosmopolita y humanista del mundo. (Bachelet, 2016, p. 75).

En sus palabras: "la idea era que pese a la diversidad de los caminos, el desarrollo predominante en América Latina era posible pensar en una convergencia pragmática, en una agenda común para potenciar los intereses mutuos y de la región en su conjunto" (Bachelet, 2016, p. 74).

De esta forma, sin abandonar el ideario de economía política liberal y su estrategia de liberalización comercial (regionalismo abierto), se abre a una práctica de flexibilidad, aceptando la coexistencia con modelos de integración que aún se mantienen bajo el ideario neoproteccionista, como el MERCOSUR, expresado en el remanente de visiones cercanas a la industrialización sustitutiva de importaciones, a través del fortalecimiento o la recuperación de empresas estatales y el papel que juega el Estado en la articulación de las relaciones entre el mercado y la sociedad.

\section{Conclusiones}

Estamos en presencia de un "cambio de época", que se manifestó a nivel sistémico en el abandono, por parte de Estados Unidos, de un ejercicio hegemónico bajo una concepción social del poder, como fueron los gobiernos de Obama (Santa Cruz, 2017); y en otros aspectos positivos, como la recomposición de relaciones diplomáticas con Cuba, que 
favorecieron la recuperación del multilateralismo en la política exterior norteamericana y el posterior retorno a un duro unilateralismo, reforzado con una práctica proteccionista que no tiene antecedentes con posterioridad a la Segunda Guerra Mundial; política que ha sido puesta en praxis por el actual gobierno de Donald Trump.

Esta política proteccionista ha dado origen a estrategias contrarias, por parte de algunos de sus estrechos aliados liberales, que dieron nacimiento al llamado TPP11 (CPTPP), con el fin de sustituir a un TTP abandonado por Washington y cuyo objetivo es mantener las tendencias liberales de apertura y multilateralismo del comercio internacional. En América Latina se percibe un interés sobre la zona más bien secundario por parte de la política exterior norteamericana, percepción que se reforzó por la decisión de Trump de no asistir a la VIII Cumbre de las Américas.

Por su parte, a nivel latinoamericano, si bien en este "cambio de época" persisten algunos elementos de fuerte fragmentación regional, como aquellos que caracterizaron el período anterior, coincidente con el unilateralismo del período de Bush hijo y el dominio del neoliberalismo, la región parece deslizarse hacia nuevas convergencias más liberales, en política, economía e integración, como consecuencia del significativo retroceso de los gobiernos y alianzas de corte populares, populistas o progresistas.

El avance del regionalismo liberal (regionalismo abierto), expresado en la atracción que está ejerciendo la AP en el entorno latinoamericano y el papel que cumplió -en particular por el liderazgo de Chile- en la concreción del TPP11, constituyen manifestaciones de este cambio de época. Al mismo tiempo, se observa un profundo retroceso del regionalismo anticapitalista (ALBA) y el inmovilismo o amesetamiento en que se mantiene el MERCOSUR, como una unión aduanera imperfecta.

El continente sudamericano se ha convertido en un gran laboratorio y en una enorme zona gris. Los gobiernos neoconservadores o liberales se encuentran atravesados por grandes dilemas. Izquierdas y progresismos en retroceso, todos parecen estar a la espera de nuevas reconfiguraciones y trayectorias de acción (De Gori, Gómez y Ester, 2017).

La pérdida del liderazgo regional del Brasil, un proceso iniciado bajo la presidencia de Dilma Rousseff y profundizado luego por su destitución, la llegada de Temer y el triunfo de Bolsonaro, dejó un lugar que comenzó a ser ocupado en forma creciente por el presidente Macri hasta la crisis que afecta a su país. Este liderazgo se advirtió respecto del regionalismo, buscando la convergencia entre el MERCOSUR y la AP, en el impulso por retomar como prioridad de política comercial internacional la búsqueda de un ALC entre MERCOSUR y la UE, y por sus posiciones en defensa de los sistemas políticos democráticos en la región, particularmente frente a Venezuela. Esta posición de liderazgo, cuestionado internamente en Chile, es el lugar al que pareciera estar aspirando el presidente Piñera, cuya excluyente agenda regional está centrada en el enfrentamiento con el gobierno venezolano. 
Las diferencias siguen persistiendo en relación con los modelos de regionalismo -ALBA, MERCOSUR, AP-, confrontaciones en declinación, debido al acercamiento que se está produciendo entre los dos últimos bloques. No hay un fortalecimiento de las relaciones con Estados Unidos a nivel regional, pero sí a nivel bilateral, debido a que Bolsonaro se ha integrado a los gobiernos con relaciones cordiales con Washington, tales los de Colombia y Chile. Por el contrario, el discurso antiliberal, antiglobalización y nacionalista, de oposición a la tradición liberal, y las iniciativas proteccionistas en el campo de la economía internacional, han provocado un acercamiento de México hacia América del Sur, mientras que en esta se advierte una línea de continuidad en la pérdida del liderazgo de Brasil, cuya posición dominante pareciera ir asumiéndola el actual presidente argentino y/o el presidente chileno. Con Dilma, Brasil fue perdiendo protagonismo, tanto en la política global como en el ámbito regional (Cervo y Lessa, 2014; Saraiva, 2016).

Por su parte, los elementos principales que identificaron el liderazgo de Macri se manifestaron en la voluntad de acercar el MERCOSUR y la AP, aceptando la visión de convergencia propuesta anteriormente por Bachelet y el acercamiento con el gobierno chileno, mientras se fueron profundizando las diferencias con Venezuela.

En relación con las ideas sobre relaciones internacionales y política exterior, no se advierten manifestaciones concretas de una renovación teórico-conceptual, manteniéndose en ese sentido aquellos marcos referenciales que habíamos caracterizado en otro trabajo (Bernal-Meza, 2016b): los nuevos aportes teóricos, como el "enfoque de economía política liberal" sostenido en el paradigma del regionalismo abierto; los aportes teóricometodológicos en el contexto sistémico posguerra fría y de globalización, en particular los que hacen referencia a las estructuras sistémicas contemporáneas, tales como "estructuras hegemónicas de poder" (Guimarães, 2005) e "insubordinación fundante” (Gullo, 2010), así como un ideario para la construcción de la independencia económica y el desarrollo, que se agregan al aggiornamiento de otras doctrinas, como la de la "autonomía", y conceptualizaciones como aquella de potencia regional; en este caso, específicamente sobre la categorización de "potencias secundarias" (Flemes, 2013), ${ }^{13}$ categoría analítica derivada de los cambios contemporáneos ocurridos en la estructura de poder regional que comenzó a utilizarse en América del Sur desde 2010.

El principal elemento para el realineamiento de los ejes de fragmentación que habían caracterizado el período previo al "cambio de época", está en la coincidencia del cambio de gobierno en Argentina y la fuerte declinación del liderazgo brasileño. En este contexto, las visiones liberales de economía política se extienden desde Chile y Colombia hacia Argentina; se desarrollan tendencias hacia la convergencia entre MERCOSUR y la Alianza

13 Flemes (2013) la aplicó a la descripción de poderes secundarios sudamericanos a ciertos países (medianos), en relación con el poder regional de Brasil. Ardila (2012, 2013) también aplicó esta al estudio del escenario latinoamericano desde la perspectiva de Colombia, como calidad que caracteriza a ciertos países por su relativo poder militar, recursos naturales, institucionales e influencia de su discurso internacional. 
del Pacífico junto a la declinación de ALBA, en coincidencia con el progresivo aislamiento regional e internacional de Venezuela.

Es en este contexto que adquiere relevancia la renovación teórico-conceptual impulsada por el saliente gobierno chileno de Michelle Bachelet. Stricto sensu, no se trata de una renovación del pensamiento chileno en política exterior, cuya tradición ha sido bien analizada (Bernal-Meza, 2015b; Artaza y Ross, 2012, 2015), sino de una expresión de pragmatismo, que le ha permitido mantener la identidad ideológico-epistémica de su política exterior, incorporando flexibilidad para facilitar el acercamiento hacia los socios regionales que comparten ahora su mirada de economía política liberal.

Evaluar cuánto pesó la incorporación del nuevo concepto de la política exterior chilena en el acercamiento con los gobiernos de Argentina y de Brasil, luego de la llegada de Macri y Temer a las respectivas presidencias, o si este acercamiento y sintonía, que posibilitó tender los primeros puentes entre la AP y el MERCOSUR, fue resultado de la llegada de gobiernos ideológicamente más afines al liberalismo chileno y a las políticas de libre mercado, es una cuestión que dilucidarán los tiempos por venir.

Frente a un escenario internacional marcado por el unilateralismo y las políticas comerciales proteccionistas de Washington, es evidente que, potencialmente, una convergencia entre la AP y el MERCOSUR sería beneficiosa para ambos bloques, ampliando el abanico de visiones liberales; unas más radicales que otras.

\section{Referencias}

Ardila, M. (2012). Potencia regional secundaria en definición: Colombia entre Sur y Centroamérica. Papel Político, 17(1), 293-319.

Ardila, M. (2013). La transición internacional colombiana y la búsqueda de un nuevo rol frente a potencias regionales en Latinoamérica. En S. Jost, (Ed.), Colombia: ¿una potencia en desarrollo? Escenarios y desafios para su política exterior (pp. 643658). Bogotá: Konrad Adenauer Stiftung.

Artaza, M. y Ross, C. (Eds.). (2012). La política exterior de Chile, 1990-2009. Del aislamiento a la integración global. Santiago: RIL Editores.

Artaza, M. y Ross, C. (Eds.). (2015). La politica exterior de Chile, 1990-2009. Santiago: RIL Editores.

Bachelet, M. (2016). Convergencia en la diversidad en la política internacional, Conferencia de S.E. la Presidenta de la República de Chile en la Academia Diplomática de Chile. Diplomacia, (133), 73-81. 
Banco Santander (2019). Cifras del comercio exterior en Brasil. Recuperado de: https://es.portal.santandertrade.com/analizar-mercados/brasil/cifras-comercioexterior

Bernal-Meza, R. (2005), Multilateralismo e unilateralismo na política mundial: América Latina frente à Orden Mundial em transiçâo. Revista Brasileira de Política Internacional, 48(1), 5-23.

Bernal-Meza, R. (2009). México: de la autonomista potencia media a socio subordinado de Estados Unidos. Revista CICLOS, 35/36, 233-278.

Bernal-Meza, R. (2012a). China y la configuración del nuevo orden internacional: las relaciones China-MERCOSUR y Chile. En R. Bernal-Meza y S. Quintanar (Eds.), Regionalismo y orden mundial: Suramérica, Europa, China (pp. 55-114). Buenos Aires: Nuevohacer y Universidad Nacional del Centro.

Bernal-Meza, R. (2012b). China-MERCOSUR and Chile Relations. En Li Xing y Steen F. Christensen (Eds.), The Rise of China. The Impact on Semi-Periphery and Periphery Countries (pp. 59-102). Aalborg: Aalborg University Press.

Bernal-Meza, R. (2012c). El escenario sudamericano frente a la globalización: regionalismos, Estado y política exterior. En R. Bernal-Meza y S. Álvarez (Eds.), Asuntos de América Latina (pp. 17-51). Santiago: Universidad de Santiago de Chile.

Bernal-Meza, R. (2013). Modelos o esquemas de integración y cooperación en curso en América latina (UNASUR, Alianza del Pacífico, ALBA, CELAC): una mirada panorámica. Berlín: Iberoamerikanisches Institut, Heft 12.

Bernal-Meza, R. (2015a). Alianza del Pacífico versus ALBA y MERCOSUR: entre el desafío de la convergencia y el riesgo de la fragmentación de Sudamérica. Pesquisa \& Debate, 47, 1-34.

Bernal-Meza, R. (2015b). Pensamiento chileno en la política exterior y en las teorías de relaciones internacionales. En Mario Artaza y César Ross (Eds.), La política exterior de Chile. Del aislamiento a la integración global 1990-2009 (pp. 21-47). Santiago: RIL Editores.

Bernal-Meza, R. (2015c). La inserción internacional de Brasil: el papel de BRICS y de la región. Universum, 30(2), 17-35.

Bernal-Meza, R. (2016a). China and Latin America Relations: The Win-Win Rhetoric. Journal of China and International Relations, Special issue, 27-43. doi:10.5278/ojs.jcir.v4i2.1588

Bernal-Meza, R. (2016b). Contemporary Latin American Thinking on International Relations: Theoretical, Conceptual and Methodological Contributions. Revista Brasileira de Política Internacional, 59(1), 1-32.

Bernal-Meza, R. (2017a). China en América Latina. Política exterior, discurso y fundamentos: diplomacia pública y percepciones en la región. En E. Pastrana 
Buelvas y H. Gehring (Eds.), La proyección de China en América Latina y el Caribe (pp. 171-187). Bogotá: Editorial Pontificia Universidad Javeriana y Konrad Adenauer Stiftung.

Bernal-Meza, R. (2017b). Las relaciones entre China y América latina y la retórica 'ganadores-ganadores'. En C. Moneta y S. Cesarín (Eds.), La tentación pragmática. China-Argentina/América Latina: lo actual, lo próximo y lo distante (pp. 25-51). Sáenz Peña: Editorial de la Universidad Nacional de Tres de Febrero.

Bernal-Meza, R. (2017c). Las relaciones internacionales de América Latina ante un cambio de época. En J. Á. Sotillo y B. Ayllón (Coords.), Las transformaciones de América Latina (pp. 120-148). Madrid: Los Libros de la Catarata.

Bernal-Meza, R. (2017d). Las ideas en el pensamiento de política exterior de Venezuela bajo la revolución bolivariana: continuidades y rupturas: 1990-2016. Revista Izquierdas, 32, 235-262. Recuperado de https://scielo.conicyt.cl/scielo.php?script=sci_arttext\&pid=S0718$50492017000100235 \& \operatorname{lng}=\mathrm{es} \& \mathrm{nrm}=\mathrm{iso} \& \operatorname{tn} \mathrm{ln}=\mathrm{es}$

Bernal-Meza, R. y Bizzozero, L. (Eds.). (2014). La política internacional de Brasil: de la región al mundo. Montevideo: Universidad de la República y Ediciones Cruz del Sur.

Bernal-Meza, R. y Christensen, S. F. (2012). Latin America's political and economic responses to the process of globalization. En M. Nilsson y J. Gustafsson (Eds.), Latin American Responses to Globalization in the $21^{\text {st }}$ Century (pp. 16-35). Basingstoke (England) y New York: Palgrave Macmillan.

Betancourt, R. (2013). Colombia frente a los espacios regionales de cooperación e integración. En S. Jost (Ed.), Colombia: ¿una potencia en desarrollo? Escenarios y desafíos para su política exterior (pp. 659-673). Bogotá: Konrad Adenauer Stiftung.

Briceño-Ruiz, J. y Morales, I. (Eds.) (2017). Post-Hegemonic Regionalism in the Americas. London-New York: Routledge.

Briones, S. y Dockendorff, A. (2015). Continuidad y cambio en la política exterior chilena en el gobierno de Sebastián Piñera (2010-2014). Estudios Internacionales, 47(180), 115-138.

Cantelmi, M. (16 de junio de 2017). Gestos, retórica y muchas dudas en la ofensiva de Trump contra Cuba. Clarín. Recuperado de: https://www.clarin.com/mundo/gestosretorica-muchas-dudas-ofensiva-trump-cuba_0_HJNJ6kz7-.html

CEPAL (2015). América Latina y el Caribe y China. Hacia una nueva era de cooperación económica. Santiago: Naciones Unidas.

Cervo, A. L. y Lessa, A. C. (2014). O declínio: inserção internacional do Brasil (20112014). Revista Brasileira de Política Internacional, 57(2), 133-151.

Christensen, S. F. y Bernal-Meza, R. (2014). Theorizing the rise of the Second World and the changing international system. En Li Xing (Ed.), The BRICS and 
Beyond. The International Political Economy of the Emergence of a New World Order (pp. 25-52). Surrey: Ashgate.

Clarín (15 de marzo de 2016). Buscan un acuerdo de libre comercio. Clarín, p. 15.

Cué, C. (15 de agosto de 2017). Mike Pence aclara que cualquier intervención en Venezuela será consensuada con Latinoamérica. El País. Recuperado de: https://elpais.com/internacional/2017/08/15/argentina/1502815632_126437.html

De Gori, E., Gómez, A. y Ester, B. (2017). Gobiernos progresistas en América Latina: cambios y permanencias tras un período de estabilidad. En J. Á. Sotillo y B Ayllón (Coords.), Las transformaciones de América Latina (pp. 17-33). Madrid: Los Libros de la Catarata.

Dussel Peters, E. (Ed.). (2016). La nueva relación comercial de América Latina y el Caribe con China. ¿Integración o desintegración regional? México D.F.: Red Académica de América Latina y el Caribe sobre China, Universidad Nacional Autónoma de México, Unión de Universidades de América Latina y Caribe y Centro de Estudios China-México.

Ellis, R. E. (2009). China in Latin America. The Whats \& Wherefores. London: Lynne Rienner Publishers.

Flemes, D. (2012a). La política exterior colombiana desde la perspectiva del realismo clásico. En S. Jost (Ed.), Colombia: ¿una potencia en desarrollo? Escenarios y desafíos para su política exterior (pp. 19-38). Bogotá: Konrad Adenauer Stiftung.

Flemes, D. (2012b). Actores estatales y regionalismo estratégico: Brasil y Colombia en el orden multipolar. En E. Pastrana, S. Jost y D. Flemes (Eds.), Colombia y Brasil: ¿socios estratégicos en la construcción de Suramérica? (pp.25-50). Bogotá: Editorial Pontificia Universidad Javeriana.

Flemes, D. (2013). La política exterior colombiana desde la perspectiva del realismo clásico. En S. Jost, (Ed.), Colombia: ¿una potencia en desarrollo? Escenarios y desafíos para su política exterior (pp. 19-37). Bogotá, Konrad Adenauer Stiftung.

Flemes, D. y Saraiva, M. G. (2014). Potências emergentes na ordem de redes: o caso do Brasil. Revista Brasileira de Política Internacional, 57(2), 214-223.

Fuentes, C. (2010). Balance crítico de la política exterior de Chile 1990-2009. En Y. Quiroga y J. Ensignia (Eds.), Chile en la Concertación (1990-2010) Tomo I (pp. 123-158). Santiago, Friedrich Ebert Stiftung.

Gajate, R. (2016). Rumbos políticos del MERCOSUR. Agenda y orientaciones políticas de una nueva etapa. En N. Mellado (Ed.), Latinoamérica: inserción global e integración regional (pp. 153-175). Córdoba: Lerner Editora.

Gattavara, F. (27 de enero de 2018). Estados Unidos sería bien recibido en el TPP. Economía y Negocios. Recuperado de http://www.economiaynegocios.cl/noticias/noticias.asp?id=438500 
Giacalone, R. (2015). El orden regional sudamericano en la segunda década del siglo XXI ¿conflicto o negociación? En N. Mellado (Ed.), Estrategias de inserción internacional e integración latinoamericana en el siglo XXI (pp. 55-77). Córdoba: Lerner Editora.

Guelar, D. (2013). La invasión silenciosa. El desembarco chino en América del Sur. Buenos Aires: Random House Mondadori S.A. y Ed. Debate.

Guimarães, S. P. (2005). Cinco siglos de periferia. Buenos Aires: Prometeo Libros.

Gullo, M. (2010). La insubordinación fundante. Breve historia de la construcción del poder de las naciones. Buenos Aires: Biblos.

Guzzini, S. (2013). From (Alleged) Unipolarity to the Decline of Multilateralism? A power-theoretical 'critique. En S. Guzzini, Power, Realism and Constructivism (pp. 61-76). Londres y New York: Routledge.

Hobsbawm, E. (2007). Historia del siglo XX (10ª ed.). Buenos Aires: Crítica.

IPEC (2015). La economía de Brasil: presente y futuro, Provincia de Santa Fe. Recuperado de:

https://www.santafe.gov.ar/index.php/web/content/download/219987/1145933/versi on/1/file/2015+julio+20+Brasil+hr.pdf

Jost, S. (Ed.). (2013). Colombia: ¿una potencia en desarrollo? Escenarios y desafíos para su política exterior (2 $2^{\text {a }}$. ed.). Bogotá: Konrad Adenauer Stiftung.

Khanna, P. (2012). Surge of the Second Worlds. The National Interest, 119, 62-9.

Lissardy, G. (26 de abril de 2018). ¿Qué cambia para América Latina con la elección de Mike Pompeo como nuevo secretario de Estado de Estados Unidos? BBC Mundo, Nueva York. Recuperado de https://www.bbc.com/mundo/noticias-america-latina43394872?ocid=socialflow_twitter

Lugones, P. (17 de junio de 2017). Cambios de Trump hacia Cuba: Solo es un cambio de narrativa, no va a afectar el curso de la apertura. Clarín. Recuperado de: https://www.clarin.com/mundo/cambios-trump-cuba-solo-cambio-narrativa-vaafectar-curso-apertura_0_rJYZeG7mW.html.

Maira, L. (2010). La política exterior de los gobiernos de la Concertación. Contexto, raíces, formulación, logros y restricciones. En Y. Quiroga y J. Ensignia (Eds.), Chile en la Concertación (1990-2010) Tomo II (pp. 63-101). Santiago: Friedrich Ebert Stiftung.

Maira, L. (2015). La política hacia México. En M. Artaza y C. Ross (Eds.), La política exterior de Chile, 1990-2009, Vol. 2 (pp. 355-374). Santiago: RIL Editores.

Malone, D. y Khong, Y. (2003). Unilateralism and U.S. Foreign Policy: International perspectives. Boulder: Center on International Cooperation Studies in Multilateralism.

Morales, R. (9 de marzo de 2018). TPP 11 se cristaliza y desafía proteccionismo de Trump. El Economista. Recuperado de https://www.eleconomista.com.mx/empresas/TPP11-se-cristaliza-y-desafia-proteccionismo-de-Trump-20180309-0012.html

106 Si Somos Americanos. Revista de Estudios Transfronterizos 
Ojeda. T. (2017). Regionalismos e integración en América Latina y el Caribe. En J. Á. Sotillo y B. Ayllón (Coords.), Las transformaciones de América Latina (pp. 149174). Madrid: Los Libros de la Catarata.

Ortiz V. S. y Dussel, E. (2016). La nueva relación comercial entre América Latina y el Caribe y China: ¿promueve la integración o desintegración comercial? En E. Dussel P. (Coord.), La nueva relación comercial de América Latina y el Caribe con China. ¿Integración o desintegración regional? (pp. 13-58). México D.F.: Red Académica de América Latina y el Caribe sobre China, Universidad Nacional Autónoma de México, Unión de Universidades de América Latina y Caribe y Centro de Estudios China-México.

Oviedo, E. (2012a). The struggle for modernization and Sino-Latin American economic relations. En L. Xing y S. F. Christensen (Eds.), The rise of China. the impact on semi-periphery and periphery countries (pp. 103-131). Aalborg: Aalborg University Press.

Oviedo, E. (2012b). Puja de modernizaciones y relaciones económicas chinolatinoamericanas en un mundo en crisis. En R. Bernal-Meza y S. Quintanar (Eds.), Regionalismo y orden mundial: Suramérica, Europa, China (pp. 115-154). Buenos Aires: Nuevohacer y Universidad Nacional del Centro de la Provincia de Buenos Aires.

Oviedo, E. (2014). Principales variables para el estudio de las relaciones entre Brasil y China. En R. Bernal-Meza y L. Bizzozero (Eds.), La política internacional de Brasil: de la región al mundo (pp. 143-166). Montevideo: Ediciones Cruz del Sur y Universidad de la República.

Pastrana, E. y Gehring, H. (Eds.). (2017). La proyección de China en América Latina y el Caribe. Bogotá: Editorial Pontificia Universidad Javeriana.

Pastrana, E. y Vera, D. (2013). Estrategias de la política exterior de Colombia en su calidad de potencia secundaria de Suramérica. En E. Pastrana, S. Jost y D. Flemes (Eds.), Colombia y Brasil: ¿ socios estratégicos en la construcción de Suramérica? (pp. 187-235). Bogotá: Editorial Pontificia Universidad Javeriana, Fundación Konrad Adenauer, German Institute of Global and Area Studies y Universidad San Buenaventura.

Pastrana, E., Betancourt, R. y Castro, R. (2014). Colombia y la Alianza del Pacífico: un proyecto regional de cara a la multipolaridad creciente. En E. Pastrana B. y H. Ghering (Eds.), Alianza del Pacífico: mitos y realidades (pp. 173-205). Cali: Universidad Santiago de Cali y Fundación Konrad Adenauer.

Pastrana, E., Castro, R. y González, P. (2017). Las relaciones entre Colombia y China: perspectivas para una asociación estratégica, comprehensiva e integral. En E. Pastrana B. y H. Gehring (Eds.), La proyección de China en América Latina y el Caribe (pp. 409-446). Bogotá: Editorial Pontificia Universidad Javeriana. 
Publimetro (13 de abril de 2018). Vemos con buenos ojos esta señal de apertura al libre comercio. Publimetro. Recuperado de https://www.publimetro.cl/cl/noticias/2018/04/13/chile-deja-la-puerta-abierta-eeuuvuelva-al-tpp-vemos-buenos-ojos-esta-senal-apertura-al-libre-comercio.html

Riggirozzi, P. y Tussie, D. (Eds.). (2012). The Rise of Post-Hegemonic Regionalism in Latin America. Dordrecht: Springer.

Romero, C. y Mijares, V. (2016). From Chávez to Maduro: Continuity and change in venezuelan foreign policy. Contexto Internacional, 38(1), 191-227.

Romero, M. C. (22 de marzo de 2018). Presidente Piñera: "No existe una política clara de la administración Trump con respecto a América Latina". Emol. Recuperado de https://www.emol.com/noticias/Nacional/2018/03/22/899724/Presidente-Pinera-Noexiste-una-politica-clara-de-la-administracion-Trump-con-respecto-a-AmericaLatina.html

Rubio, L. y Kaufman S. (Eds.). (2004). Mexico under Fox. Londres: Lynne Rienner Publishers.

Sanahuja, J. A. (2012). Regionalismo postliberal y multilateralismo en Sudamérica. En A. Serbin, L. Martínez y H. Ramanzini Junior (Eds.), El regionalismo postliberal en América Latina y el Caribe: nuevos actores, nuevos temas, nuevos desafíos (pp. 1972). Buenos Aires: CRIES.

Sanahuja, J. A. (2018). Crisis de globalización, crisis de hegemonía: un escenario de cambio estructural para América Latina y el Caribe. En A. Serbin (Ed.), América Latina y el Caribe frente a un Nuevo Orden Mundial: Poder, globalización y respuestas regionales (pp. 37-68). Buenos Aires: CRIES.

Santa Cruz, A. (2017). La hegemonía estadounidense es lo que el presidente hace de ella: política exterior y multilateralismo durante las administraciones Obama. Estudios Internacionales, 187, 85-107.

Saraiva, M. G. (2016). Estancamento e crise da liderança do Brasil no entorno regional. En A. Serbin (Coord.), ¿Fin de ciclo y reconfiguración regional? América Latina y las relaciones entre Cuba y los Estados Unidos (pp. 295-310). Buenos Aires: CRIES.

Serbin, A. (2012). Déficit democrático y participación ciudadana en el marco del regionalismo postliberal. En A. Serbin, L. Martínez y H. Ramanzini Junior (Eds.), El regionalismo postliberal en América Latina y el Caribe: nuevos actores, nuevos temas, nuevos desafíos (pp. 73-129). Buenos Aires: CRIES.

Serbin, A. (2018). América Latina y el Caribe frente a un nuevo orden mundial: crisis de la globalización, reconfiguración global del poder y respuestas regionales. En A. Serbin (Ed.), América Latina y el Caribe frente a un Nuevo Orden Mundial: Poder, globalización y respuestas regionales (pp. 13-33). Buenos Aires: CRIES.

Sevares, J. (2015). China. Un socio imperial para Argentina y América Latina. Buenos Aires: Editorial Edhasa. 
Soy Chile (12 de abril de 2018). Donald Trump considera reingresar a Estados Unidos al TPP. Soy Chile. Recuperado de http://www.soychile.cl/Santiago/Internacional/2018/04/12/527739/Donald-Trumpconsidera-reingresar-a-Estados-Unidos-al-TPP.aspx

Stewart, P. y Forman, S. (2002). Multilateralism \& U.S. Foreign Policy. Ambivalent Engagement. Boulder: Lynne Rienner Publishers.

Stuenkel, O. (2015). The BRICS and the Future of Global Order. Lanham: Lexington Books.

Teletrece (29 de octubre de 2018). El primer viaje de Jair Bolsonaro será a Chile. Teletrece. Recuperado de http://www.t13.cl/noticia/mundo/el-primer-viaje-jair-bolsonaro-serachile

Voa Noticias (1 de diciembre de 2018). EE.UU. promete más oportunidades para la región y advierte sobre China. Voa Noticias. Recuperado de https://www.voanoticias.com/a/mike-pompeo-entrevista-voa-mas-oportunidadesregion-latinoamerica-g20-china-no-confiable/4682648.html 